\title{
Coagulation abnormalities and bleeding in pregnancy: an anesthesiologist's perspective
}

\section{Hea-Jo Yoon}

Department of Anesthesiology and Pain Medicine, Ilsan Jeil Hospital, Goyang, Korea

During pregnancy, the procoagulant activity increases (manifested by elevation in factor VII, factor VIII, factor X, and fibrinogen levels), while the anticoagulant activity decreases (characterized by reduction in fibrinolysis and protein $S$ activity), resulting in hypercoagulation. Standard coagulation tests, such as prothrombin time or activated partial thromboplastin time, are still used despite the lack of evidence supporting its accuracy in evaluating the coagulation status of pregnant women. Thromboelastography and rotational thromboelastometry, which are used to assess the function of platelets, soluble coagulation factors, fibrinogen, and fibrinolysis, can replace standard coagulation tests. Platelet count and function and the effect of anticoagulant treatment should be assessed to determine the risk of hematoma associated with regional anesthesia. Moreover, anesthesiologists should monitor patients for postpartum hemorrhage (PPH), and attention should be paid when performing rapid coagulation tests, transfusions, and prohemostatic pharmacotherapy. Transfusion of a high ratio of plasma and platelets to red blood cells (RBCs) showed high hemostasis success and low bleeding-related mortality rates in patients with severe trauma. However, the effects of high ratios of plasma and platelets and the ratio of plasma to RBCs and platelets to RBCs in the treatment of massive PPH were not established. Intravenous tranexamic acid should be administered immediately after the onset of postpartum bleeding. Pre-emptive treatment with fibrinogen for PPH is not effective in reducing bleeding. If fibrinogen levels of less than $2 \mathrm{~g} / \mathrm{L}$ are identified, 2-4 g of fibrinogen or 5-10 ml/kg cryoprecipitate should be administered.

Keywords: Blood transfusion; Conduction anesthesia; Fibrinogen; Postpartum hemorrhage; Tranexamic acid.

\section{INTRODUCTION}

The physiology of coagulation in pregnant women differs from that in men or in women who are not pregnant. Pregnant women frequently develop physiological anemia and experience changes in the levels of coagulation factors that alter the balance between coagulation and bleeding in preparation for bleeding during birth. Anesthesiologists should understand both physiological changes in the coagulation system and disease- and medication-induced pathophysiological changes during pregnancy and increase the safety of regional anesthesia for painless delivery and cesarean section. According to Vandermeulen et al. [1], spinal hematoma following the administration of regional anesthesia was associated with coagulation abnormalities in $68 \%$ of cases. In addition, obstetrical bleeding is the major cause of maternal mortality [2]. Although much progress has been made in the management of massive bleeding after conducting vigorous research, most study participants were trauma patients rather than pregnant women [3]. Massive bleeding caused by trauma and postpartum hemorrhage (PPH) differ in terms of the gender and coagulation mechanisms of the subjects;

This is an Open Access article distributed under the terms of the Creative Commons Attribution Non-Commercial License (http://creativecommons.org/licenses/by-nc/4.0) which permits unrestricted non-commercial use, distribution, and reproduction in any medium, provided the original work is properly cited. 
therefore, PPH requires an evidence-based treatment from the perspective of internal medicine, which is different from that used for treating bleeding caused by trauma [4].

This study takes an anesthesiologist's perspective to examine the changes in coagulation-related factors. It also aims to determine the risk for coagulation during pregnancy, incidence of hereditary or acquired coagulation disorders in pregnant women, risk for regional anesthesia administration in pregnant women with coagulation abnormalities, rate of transfusion in women with $\mathrm{PPH}$, and pharmacological treatment for pregnant women with coagulation disorders under special circumstances such as intrauterine fetal death.

\section{CHANGES IN COAGULATION-RELATED FACTORS DURING PREGNANCY}

During pregnancy, the levels of factor VII, factor VIII, and factor $\mathrm{X}$ increase along with fibrinogen, while fibrinolysis and the activity of protein S decrease, resulting in hypercoagulation [5]. The level of fibrinogen increases significantly from the 28th week of pregnancy and is two times higher (350-650 $\mathrm{mg} / \mathrm{dl}$ ) than that in non-pregnant women (200-400 mg/ dl) at the end of pregnancy [4]. D-dimer level also increases throughout pregnancy; at the end of pregnancy, the level exceeds the level used to diagnose thromboembolism in nonpregnant population [4].

\section{TESTS FOR COAGULATION STATUS}

\section{Standard (traditional) coagulation test}

Prothrombin time/international normalized ratio or activated partial thromboplastin time has been used to diagnose coagulation disorders and to assess coagulation disorder correction or hemostasis. Haas et al. [6] reviewed 11 mass transfusion or perioperative bleeding management guidelines and 64 studies that examined the efficacy of standard coagulation tests. They could not identify well-founded and well-designed studies that demonstrated the usefulness of standard coagulation tests in the diagnosis of coagulation disorders and hemostasis [6].

Although the prothrombin time/international normalized ratio and activated partial thromboplastin time are suitable methods for evaluating the coagulation status in patients re- ceiving warfarin and heparin treatment, respectively, it is difficult to properly evaluate the coagulation status in patients with clinical bleeding [7]. Moreover, the results of standard coagulation tests are usually obtained $1 \mathrm{~h}$ after [8]. Nevertheless, results of traditional standard coagulation tests are still used as a basis to determine the need for blood transfusions, as new standard tests to measure coagulation status are not yet established [9].

\section{Fibrinogen}

A few studies have reported fibrinogen as an important predictor of PPH $[10,11]$. Fibrinogen level less than $2 \mathrm{~g} / \mathrm{L}$ can predict $\mathrm{PPH}$ with $100 \%$ positive predictability and $99.3 \%$ specificity and is an independent variable that predicts the need for invasive techniques such as artery ligation, embolization, and hysterectomy [10-12]. When fibrinogen level exceeded $4 \mathrm{~g} / \mathrm{L}$, the outcome of PPH was good, with $79 \%$ negative predictability [10].

\section{Thromboelastography (TEG)/rotational thromboelastometry (ROTEM)}

TEG or ROTEM can replace the standard coagulation test by measuring the overall process of hemostasis in whole blood [13]. These tests are used to measure platelet, soluble coagulation factor, and fibrinogen levels and determine the role of fibrinolysis [13]. As fibrinogen is recognized as a predictor of severe $\mathrm{PPH}$, the need for rapid testing for hypofibrinogenemia is becoming apparent [10]. TEG and ROTEM are gaining attention because they can be used to diagnose hypofibrinogenemia and verify the effectiveness of fibrinogen supplement therapy while being the only test that can detect excessive fibrinolysis [13,14]. By measuring the amplitude of FIBTEM, which is a type of ROTEM that measures fibrinogen levels, the level of fibrinogen can be estimated within $5 \mathrm{~min}$ [14]. In addition, FIBTEM amplitude is an independent variable for predicting massive bleeding $(>2,500 \mathrm{ml})$, the need for transfusion of red blood cells, and the duration of ICU stay [15]. However, only a few studies have reported the accuracy of TEG and ROTEM in predicting the development of hematomas during regional anesthesia [16]. Hydroxyethyl starch (HES) can cause coagulation disorder and may have an effect on coagulation tests [17]. The use of HES in patients undergo- 
ing cesarean section can extend the clot reaction time and kinetic time of TEG, although the values are still within the normal range [18].

The 2019 Network for the Advancement of Patient Blood Management, Haemostasis and Thrombosis (NATA) PPH guidelines recommend monitoring the coagulation status of PPH patients and using laboratory tests including traditional standard tests (platelets, prothrombin time, international normalized ratio, activated partial thromboplastin time, and fibrin level) or TEG/ROTEM to determine the need for goaloriented transfusion strategies and administering hemostasis-inducing drugs [9].

\section{HEREDITARY COAGULATION DISORDERS}

Von Willebrand disease or hemophilia (carrier) is a representative hereditary disorder in pregnant women. Regional anesthesia and normal vaginal delivery are possible in patients with hereditary coagulation disorders [8]. In the case of a severe coagulation disorder, the blood coagulation factor levels should be maintained within normal range for 3-5 days following an uncomplicated vaginal delivery or 5-7 days following a cesarean section [19]. Moreover, tranexamic acid, 1-desamino-9-d-arginine vasopressin (DDAVP), recombinant protein, and plasma or cryoprecipitate can be used to treat coagulation disorders [8]. After treating the coagulation disorders, the use of anticoagulants should be considered to prevent deep thrombosis [8].

\section{ACQUIRED COAGULATION DISORDERS}

\section{Platelet disease}

Platelet abnormalities are the most common blood disorder during pregnancy and can be categorized into platelet count and platelet function disorders [8]. Platelet count of $150 \times 10^{9} / \mathrm{L}$ or less is used as a criterion for diagnosing thrombocytopenia during pregnancy [20]. Ninety-nine percent of thrombocytopenia cases during pregnancy are associated with hypertensive diseases such as preeclampsia, gestational thrombocytopenia, or idiopathic thrombocytopenic purpura [8]. In addition, platelet count should be evaluated to help in the diagnosis of premature placental detachment and deter- mine if the patient recently received an anticoagulant therapy [21].

The platelet level in pregnant women with gestational thrombocytopenia or idiopathic thrombocytopenic purpura is usually stable and within normal range $[8,22]$. On the contrary, the platelet count in patients with preeclampsia changes rapidly, requiring continuous platelet measurement; and the platelet function in severe preeclampsia patients may be reduced [22]. Pregnant women with mild or moderate preeclampsia may receive regional anesthesia based on the platelet count and coagulation test results obtained within 6 $\mathrm{h}$ [21]. However, in patients with severe preeclampsia, preeclampsia, and HELLP (hemolysis, elevated liver enzymes, and low platelets) syndrome, platelet counts and coagulation tests should be performed immediately prior to the administration of regional anesthesia, as the platelet count may decrease rapidly [21]. The incidence of spinal hematoma associated with the use of epidural anesthesia in preeclamptic pregnant women with thrombocytopenia is very low, and only one case was reported [23].

The plasma platelet levels that are associated with a high incidence of hematoma after the administration of regional anesthesia were not, even if agreed upon by experts, reported in clinical trials; hence, it is difficult to mention a specific value, but reference platelet levels have been suggested in several studies [8,21]. In healthy pregnant women, the risk for hematoma does not increase in patients with a platelet count of $100 \times 10^{9} / \mathrm{L}$ or above, and the level does not decrease at a platelet count of $75 \times 10^{9} / \mathrm{L}$; hence, regional anesthesia can be administered in pregnant women with these values in the absence of other risk factors [21,24]. Thrombocytopenia occurring in pregnant women with preeclampsia can be accompanied by other coagulation disorders, and a coagulation disorder test should be performed when platelet count is below $100 \times 10^{9} / \mathrm{L}$ [21]. If the result of the coagulation disorder test is normal, regional anesthesia may be administered in pregnant women with a platelet count of $75 \times 10^{9} / \mathrm{L}$, taking into account the rate at which platelet decreases [25]. In idiopathic thrombocytopenic purpura and gestational thrombocytopenia, regional anesthesia can be administered if the platelet count is greater than $50 \times 10^{9} / \mathrm{L}$ and stable [21]. Referring to the report that hematologists have performed lumbar puncture without sequelae using a needle that is thicker than the needle for spinal anesthesia used in obstetric anesthesia, 
spinal anesthesia may be administered in pregnant women with a platelet count of $50 \times 10^{9} / \mathrm{L}$ or less [21]. In addition, spinal anesthesia can be safely administered, even if the platelet count is less than $40 \times 10^{9} / \mathrm{L}$, in the absence of other coagulation disorders $[21,26]$.

\section{Pregnant women who use anticoagulants}

Caution is required for pregnant women who use drugs that affect coagulation. Table 1 summarizes the time required after injection of regional anesthetics (basically neuraxial anesthesia in pregnant women with normal kidney function), drug injected during epidural catheterization, and anticoagulant injected after regional anesthesia or catheter removal in pregnant women who use anticoagulants.

\section{RELATIVE RISK OF REGIONAL ANESTHESIA AND PERIPHERAL NERVE BLOCK}

The likelihood of developing hematoma after administering regional anesthesia or peripheral nerve block decreases in the following order: the risk increases after epidural anes- thesia with catheterization, while the risk decreases after administering epidural anesthesia without catheterization, spinal anesthesia, paravertebral block, deep block (celiac plexus block, stellate ganglion block, etc.), superficial perivascular blocks (popliteal sciatic block, femoral nerve block, etc.), fascia block (ilio-inguinal block, Ilio-hypogastric block, etc.), superficial block (brachial nerve block, Bier's block, etc.), and regional anesthesia [21]. Catheterization is more dangerous than one-time injection, and there is a risk for catheter removal [21]. Ultrasound-guided regional anesthesia can reduce vascular rupture, thereby reducing the risk of clavicle block in patients with coagulation disorders [21].

\section{RISK ASSOCIATED WITH REGIONAL ANESTHESIA IN PREGNANT WOMEN WITH COAGULATION DISORDERS}

The relative risks of spinal cord compression and permanent injury due to vertebral hematoma during the administration of neuraxial anesthesia in pregnant women with coagulation disorders are listed in Table 2.

Table 1. Recommendations related to Drug Use that Affect Coagulation

\begin{tabular}{|c|c|c|c|}
\hline Drug & $\begin{array}{l}\text { Acceptable time after drug for } \\
\text { block performance }\end{array}$ & $\begin{array}{l}\text { Administration of drug while spinal } \\
\text { or epidural catheter in place }\end{array}$ & $\begin{array}{c}\text { Acceptable time after block } \\
\text { performance or catheter removal } \\
\text { for next drug dose }\end{array}$ \\
\hline \multicolumn{4}{|l|}{ Heparins } \\
\hline UFH sc prophylaxis & $4 \mathrm{~h}$ or normal aPTT & Caution & $1 \mathrm{~h}$ \\
\hline UFH iv treatment & $4 \mathrm{~h}$ or normal aPTT & Caution & $4 \mathrm{~h}$ \\
\hline LMWH sc prophylaxis & $12 \mathrm{~h}$ & Caution & $4 \mathrm{~h}$ \\
\hline LMWH sc treatment & $24 \mathrm{~h}$ & Not recommended & $4 \mathrm{~h}$ \\
\hline \multicolumn{4}{|l|}{ Antiplatelet drugs } \\
\hline NSAIDs & No additional precautions & No additional precautions & No additional precautions \\
\hline Aspirin & No additional precautions & No additional precautions & No additional precautions \\
\hline Clopidogrel & 7 days & Not recommended & $6 \mathrm{~h}$ \\
\hline Prasugrel & 7 days & Not recommended & $6 \mathrm{~h}$ \\
\hline \multicolumn{4}{|l|}{ Oral anticoagulants } \\
\hline Warfarin & INR $\leq 1.4$ & Not recommended & After catheter removal \\
\hline $\begin{array}{l}\text { Rivaroxaban prophylaxis } \\
(\mathrm{CrCl}>30 \mathrm{ml} / \mathrm{min})\end{array}$ & $18 \mathrm{~h}$ & Not recommended & $6 \mathrm{~h}$ \\
\hline \multicolumn{4}{|l|}{ Thrombolytic drugs } \\
\hline $\begin{array}{l}\text { Alteplase, anistreplase, } \\
\text { reteplase, and streptokinase }\end{array}$ & 10 days & Not recommended & 10 days \\
\hline
\end{tabular}

UFH: unfractionated heparin, sc: subcutaneous, aPT: activated partial thromboplastin time, iv: intravenous, LMWH: low molecular weight heparin, NSAIDs: non-steroidal anti-inflammatory drugs, INR: international normalized ratio, CrCl: creatinine clearance. Modified from the article of HarropGriffiths et al. Anaesthesia 2013;68:966-72 [21]. 
Table 2. Relative Risks associated with Neuraxial Blocks in Obstetric Patients with Coagulation Abnormalities

\begin{tabular}{|c|c|c|c|c|}
\hline Risk factor & Normal risk & Increased risk & High risk & Very high risk \\
\hline LMWH - prophylactic dose & $>12 \mathrm{~h}$ & $6-12 \mathrm{~h}$ & $<6 \mathrm{~h}$ & $<6 h$ \\
\hline LMWH - therapeutic dose & $>24 \mathrm{~h}$ & $12-24 \mathrm{~h}$ & $6-12 \mathrm{~h}$ & \\
\hline UFH - infusion & $\begin{array}{l}\text { Stopped }>4 \mathrm{~h} \text { and APPT } \leq \\
1.4\end{array}$ & & & APPT above normal range \\
\hline $\begin{array}{l}\text { UFH - prophylactic bolus } \\
\text { dose }\end{array}$ & Last given $>4 \mathrm{~h}$ & Last given $<4 \mathrm{~h}$ & & \\
\hline NSAID + aspirin & Without LMWH & With LMWH dose $12-24 \mathrm{~h}$ & With LMWH dose $<12 \mathrm{~h}$ & \\
\hline Warfarin & INR $\leq 1.4$ & INR 1.4-1.7 & INR 1.7-2.0 & INR $>2.0$ \\
\hline General anesthesia & $\begin{array}{l}\text { Starved, not in labor, } \\
\text { antacids given }\end{array}$ & & Full stomach or in labor & \\
\hline Preeclampsia & $\begin{array}{c}\text { Platelets }>100 \times 10^{9} / \mathrm{L} \\
\text { within } 6 \mathrm{~h} \text { of block }\end{array}$ & $\begin{array}{l}\text { Platelets } 75-100 \times 10^{9} / \mathrm{L} \\
\text { (stable) and normal } \\
\text { coagulation tests }\end{array}$ & $\begin{array}{l}\text { Platelets } 75-100 \times 10^{9} / \mathrm{L} \\
\text { (decreasing) and normal } \\
\text { coagulation tests }\end{array}$ & $\begin{array}{l}\text { Platelets }<75 \times 10^{9} / \mathrm{L} \text { or } \\
\text { abnormal coagulation } \\
\text { tests with indices } \geq 1.5 \\
\text { or HELLP syndrome }\end{array}$ \\
\hline $\begin{array}{l}\text { Idiopathic } \\
\text { thrombocytopenia }\end{array}$ & $\begin{array}{c}\text { Platelets }>75 \times 10^{9} / \mathrm{L} \\
\text { within } 24 \mathrm{~h} \text { of block }\end{array}$ & Platelets $50-75 \times 10^{9} / \mathrm{L}$ & Platelets $20-50 \times 10^{9} / \mathrm{L}$ & Platelets $<20 \times 10^{9} / \mathrm{L}$ \\
\hline Intra-uterine fetal death & $\begin{array}{l}\text { FBC and coagulation tests } \\
\text { normal }\end{array}$ & $\begin{array}{l}\text { No clinical problems but } \\
\text { no investigation results } \\
\text { available }\end{array}$ & & $\begin{array}{l}\text { With abruption or overt } \\
\text { sepsis }\end{array}$ \\
\hline Cholestasis & INR $\leq 1.4$ within $24 \mathrm{~h}$ & $\begin{array}{l}\text { No other clinical problems } \\
\text { but no investigation } \\
\text { results available }\end{array}$ & & \\
\hline
\end{tabular}

LMWH: low molecular weight heparin, UFH: unfractionated heparin, aPTT: activated partial thromboplastin time, INR: international normalized ratio. Modified from the article of Harrop-Griffiths et al. Anaesthesia 2013;68:966-72 [21].

\section{RISK OF REGIONAL ANESTHESIA IN PREGNANT WOMEN WITH COAGULATION DISORDERS UNDER SPECIAL CIRCUMSTANCES}

After intrauterine fetal death (particularly 2 weeks after fetal death), there is a high likelihood of developing coagulation abnormalities and sepsis [27]. Coagulation abnormalities occur in $3 \%$ of patients who experienced uncomplicated intrauterine fetal death and in $13 \%$ of patients with placental detachment or uterine perforation [27]. The timing of onset for coagulation disorders varies and can progress rapidly; hence, it is important to know the patients' coagulation status to determine the risk for intrauterine fetal death [21].

Because trauma can cause coagulation disorders due to shock, hemodilution, hypothermia, acidemia, and inflammation, it is advisable to identify the coagulation status before administering regional anesthesia in patients with severe traumas [21]. Severe sepsis is a contraindication to regional anesthesia, as it can lead to coagulation disorders as well as consumptive coagulopathy and can increase the incidence of epidural abscess or meningitis [21]. In severe cases of uremia, platelet count and function tests are required, and platelet function may be improved by administering DDAVP [21]. The residual effects of anticoagulants should be assessed in dialysis patients receiving heparin, and the heparin effect should be reversed, if necessary $[21,28]$. If heparin was administered in dialysis patients who received regional anesthesia, caution must be taken during catheter removal to prevent bleeding [21] As all coagulation factors except for coagulation factor VIII are synthesized in the liver, liver failure is associated with coagulation disorders and coagulation tests should be performed before administering regional anesthesia [21,28]. In addition, hypersplenism may result in platelet count decrease and platelet dysfunction $[21,28]$. In mass transfusions, coagulation disorders may occur due to dilution and consumption of coagulation factors, and platelet function should be assessed if the patient has a history of platelet transfusion as this can lead to platelet dysfunction [21,29]. Disseminated coagulation disorders are consumptive coagulopathies, contraindicated in regional anesthesia, and should be blocked where they can be compressed with peripheral nerve blocks [21]. 


\section{MEDICAL TREATMENT OF PPH}

Obstetrical bleeding is a major cause of uterine atony, but it can also be caused by premature placenta detachment, placenta accrete, amniotic embolism, and consumptive coagulopathy [30]. Anesthesiologists and physicians are advised to actively intervene when there is massive bleeding or if early bleeding occurs in patients with severe $\mathrm{PPH}$, even in the absence of cardiovascular instability [9]. The main components of the medical treatment of PPH are rapid testing of coagulation disorders, transfusion therapy, and prohemostatic pharmacotherapy as adjuvant therapies [17].

\section{Transfusion}

A large-scale cohort study conducted among patients with massive bleeding from trauma reported that a higher ratio of plasma and platelets to red blood cells during transfusion reduced the rate of mortality within 24 hours after hospitalization [31]. A four-year retrospective study of 142 patients reported a reduction in the incidence of interventional procedures when blood transfusions were performed with a serum to erythrocyte ratio of 1:2 or higher [32]. In addition, a randomized study of 680 patients with severe trauma published in JAMA in 2015 had the following conclusion. Patients with severe trauma and massive bleeding did not show a difference in the overall 24-h and 30-day mortalities when transfusion was performed with plasma, platelet, and erythrocyte ratio of 1:1:1 and 1:1:2. However, hemostasis success rate was higher in the patient group with 1:1:1 ratio and had a lower bleeding-related mortality rate within $24 \mathrm{~h}$ [33]. However, in the absence of a large, well-designed, randomized study of $\mathrm{PPH}$ patients, it is difficult to determine the appropriate plasma, platelet, and erythrocyte ratios for transfusions in pregnant women with PPH. The guidelines for the management of coagulation disorders related to $\mathrm{PPH}$ in the International Society of Thrombosis and Haemostasis are against the 1:1:1-ratio transfusions of plasma, platelet, and erythrocytes and recommended fibrinogen supplementation (cryoprecipitates or fibrinogen concentrate transfusion) and platelet transfusion if it is difficult to obtain coagulation test results after transfusing 8 units of red blood cells and fresh frozen plasma [34]. Some studies have shown that vascular endothelial glycocalyx, which protects the blood vessels, is damaged in patients with traumatic bleeding, and that plasma transfusions have been reported to reduce glycocalyx degradation, autoheparinization, and bleeding $[35,36]$. These studies emphasize that blood transfusions not only replenish plasma components but also protect the blood vessels [36]. The vascular endothelium in pregnant women, especially those with HELLP syndrome, has damaged glycocalyx; therefore, the plasma components may be expected to play a protective role in pregnant women [37].

NATA guidelines recommend a restrictive erythrocyte transfusion policy that considers erythrocyte transfusion only if hemoglobin levels are less than $7 \mathrm{~g} / \mathrm{dl}$ for PPH unless in cases of massive bleeding, and 15 to $20 \mathrm{ml} / \mathrm{kg}$ plasma transfusion for coagulation abnormality in pregnant women with severe PPH NATA [9].

\section{Pharmacologic treatment of coagulation abnor- malities caused by PPH}

\section{Antifibrinolytic therapy}

Antifibrinolytic agents such as tranexamic acid inhibit fibrinase activity and stabilize fibrin clots [17]. Tranexamic acid reduces perioperative bleeding by interfering with fibrin degradation by plasmin without any special side effects [38]. In their meta-analysis, Ferrer et al. [39] reported that preadministration of tranexamic acid in patients who underwent cesarean sections or vaginal delivery can reduce bleeding.

A randomized study was conducted in 20,000 individuals to examine the effects of early administration of tranexamic acid [40]. This study was performed in patients with a clinical diagnosis of PPH after cesarean section or vaginal delivery. If postpartum bleeding occurred, $1 \mathrm{~g}$ of tranexamic acid was given as an intravenous (IV) injection; if postpartum bleeding continued for $30 \mathrm{~min}$ or if bleeding re-occurred within 24 $\mathrm{h}$, an additional $1 \mathrm{~g}$ was injected intravenously. Tranexamic acid reduced PPH mortality. Previous studies suggested that tranexamic acid should be administered as soon as the bleeding begins (within $3 \mathrm{~h}$ after delivering the fetus). The incidence of thromboembolism was not correlated with the administration of tranexamic acid [40].

The NATA guidelines recommended the IV injection of 0.5 to $1.0 \mathrm{~g}$ of tranexamic acid along with oxytocin if there is a high likelihood of PPH upon cesarean section and the IV injection of $1 \mathrm{~g}$ of tranexamic acid as soon as postpartum bleed- 
ing begins within $3 \mathrm{~h}$, with an additional $1 \mathrm{~g}$ of tranexamic acid as via IV injection if postpartum bleeding continues after $30 \min [9]$.

\section{Fibrinogen supplementation}

Low fibrinogen levels in the early stages of PPH have been associated with excessive bleeding and transfusion in several observational studies [10,11]. Cryoprecipitates and fibrinogen concentrates can be used to supplement fibrinogen, both of which contain more fibrinogen than plasma [17]. Fibrinogen concentrate differs from cryoprecipitates in that it contains less germs and can be used within 10 to $15 \mathrm{~min}$ (cryoprecipitates take more than 30 min to thaw) [41]. Cryoprecipitates, however, has von Willebrand factor, coagulation factor VIII, and coagulation factor XIII as well as fibrinogen [41]. Although fibrinogen concentrates are widely used to correct hypofibrinolysis, it remains unclear whether fibrinogen concentrates reduce bleeding $[42,43]$.

In a randomized study conducted in patients with severe PPH (blood loss of at least $1 \mathrm{~L}$ after vaginal delivery or at least $0.5 \mathrm{~L}$ after placenta removal in vaginal delivery, and blood loss of at least $1 \mathrm{~L}$ during cesarean section) who had normal fibrinogen level prior to $\mathrm{PPH}$ but whose plasma fibrinogen level was not identified, the administration of $2 \mathrm{~g}$ of fibrinogen concentrate as a treatment for $\mathrm{PPH}$ could not reduce the frequency of transfusions although it did increase the level of plasma fibrinogen [44]. Therefore, it is advisable to assess the plasma level of fibrinogen and administer 2-4 g of fibrinogen or $5-10 \mathrm{ml} / \mathrm{kg}$ of cryoprecipitates only when fibrinogen level is $2 \mathrm{~g} / \mathrm{L}$ (or ROTEM FIBTEM A5 $<12 \mathrm{~mm}$ or TEG FF MA $<14$ $\mathrm{mm})[9]$.

\section{Prevention of thromboembolism}

Correction of coagulation abnormality is important in severe $\mathrm{PPH}$, but care must also be taken to prevent thromboembolism; the NATA guidelines recommend that prevention of thromboembolism be initiated if bleeding stabilizes after severe PPH and transfusion [9].

\section{CONCLUSION}

Regional anesthesia is often used in pregnant women. Therefore, when anesthesia is administered in pregnant women with coagulation disorders or in those using heparin and antiplatelet agents, the anesthesiologists should accurately identify the coagulation status of individual patients according to the procedure or the processes involved in the procedure (e.g., catheter removal after epidural anesthesia administration). Compared with traditional standard laboratory tests, field tests such as TEG and ROTEM can quickly diagnose a wider range of coagulation disorders [13]. In addition, anesthesiologists should be actively involved as part of a multidisciplinary team from the onset of PPH. In patients with severe $\mathrm{PPH}$, the active use of plasma, platelets, and fibrinogen should be considered, and tranexamic acid, which is currently the most justified treatment, should be administered $[9,40]$.

\section{SUPPLEMENTARY MATERIALS}

Supplementary data containing Korean version of this article is available at https://doi.org/10.17085/apm.2019.14.4.371.

\section{CONFLICTS OF INTEREST}

No potential conflict of interest relevant to this article was reported.

\section{REFERENCES}

1. Vandermeulen EP, Van Aken H, Vermylen J. Anticoagulants and spinal-epidural anesthesia. Anesth Analg 1994; 79: 1165-77.

2. Hogan MC, Foreman KJ, Naghavi M, Ahn SY, Wang M, Makela SM, et al. Maternal mortality for 181 countries, 1980-2008: a systematic analysis of progress towards Millennium Development Goal 5. Lancet 2010; 375: 1609-23.

3. Spahn DR, Bouillon B, Cerny V, Coats TJ, Duranteau J, Fernández-Mondéjar E, et al. Management of bleeding and coagulopathy following major trauma: an updated European guideline. Crit Care 2013; 17: R76.

4. Szecsi PB, Jørgensen M, Klajnbard A, Andersen MR, Colov NP, Stender S. Haemostatic reference intervals in pregnancy. Thromb Haemost 2010; 103: 718-27.

5. Cerneca F, Ricci G, Simeone R, Malisano M, Alberico S, Guaschino S. Coagulation and fibrinolysis changes in normal pregnancy. Increased levels of procoagulants and reduced levels of inhibitors during pregnancy induce a hypercoagulable state, combined with a reactive fibrinolysis. Eur J Obstet Gynecol Reprod Biol 1997; 73: 31-6. 
6. Haas T, Fries D, Tanaka KA, Asmis L, Curry NS, Schöchl H. Usefulness of standard plasma coagulation tests in the management of perioperative coagulopathic bleeding: is there any evidence? Br J Anaesth 2014; 114: 217-24.

7. de Lange NM, Lancé MD, de Groot R, Beckers EA, Henskens YM, Scheepers HC. Obstetric hemorrhage and coagulation: an update. Thromboelastography, thromboelastometry, and conventional coagulation tests in the diagnosis and prediction of postpartum hemorrhage. Obstet Gynecol Surv 2012; 67: 426-35.

8. Katz D, Beilin Y. Disorders of coagulation in pregnancy. Br J Anaesth 2015; 115 Suppl 2: ii75-88.

9. Muñoz M, Stensballe J, Ducloy-Bouthors AS, Bonnet MP, De Robertis E, Fornet I, et al. Patient blood management in obstetrics: prevention and treatment of postpartum haemorrhage. A NATA consensus statement. Blood Transfus 2019; 17: 112-36.

10. Charbit B, Mandelbrot L, Samain E, Baron G, Haddaoui B, Keita $\mathrm{H}$, et al. The decrease of fibrinogen is an early predictor of the severity of postpartum hemorrhage. J Thromb Haemost 2007; 5: 266-73.

11. Gayat E, Resche-Rigon M, Morel O, Rossignol M, Mantz J, Nicolas-Robin A, et al. Predictive factors of advanced interventional procedures in a multicentre severe postpartum haemorrhage study. Intensive Care Med 2011; 37: 1816-25.

12. Cortet M, Deneux-Tharaux C, Dupont C, Colin C, Rudigoz RC, Bouvier-Colle $\mathrm{MH}$, et al. Association between fibrinogen level and severity of postpartum haemorrhage: secondary analysis of a prospective trial. Br J Anaesth 2012; 108: 984-9.

13. Whiting D, DiNardo JA. TEG and ROTEM: technology and clinical applications. Am J Hematol 2014; 89: 228-32.

14. Huissoud C, Carrabin N, Benchaib M, Fontaine O, Levrat A, Massignon D, et al. Coagulation assessment by rotation thrombelastometry in normal pregnancy. Thromb Haemost 2009; 101: 755-61.

15. Collins PW, Lilley G, Bruynseels D, Laurent DB, Cannings-John R, Precious E, et al. Fibrin-based clot formation as an early and rapid biomarker for progression of postpartum hemorrhage: a prospective study. Blood 2014; 124: 1727-36.

16. De Pietri L, Bianchini M, Montalti R, De Maria N, Di Maira T, Begliomini B, et al. Thrombelastography-guided blood product use before invasive procedures in cirrhosis with severe coagulopathy: A randomized, controlled trial. Hepatology 2016; 63: 566-73.

17. Ducloy-Bouthors AS, Susen S, Wong CA, Butwick A, Vallet B, Lockhart E. Medical advances in the treatment of postpartum hemorrhage. Anesth Analg 2014; 119: 1140-7.

18. Butwick A, Carvalho B. The effect of colloid and crystalloid preloading on thromboelastography prior to Cesarean delivery. Can J Anaesth 2007; 54: 190-5.
19. Peyvandi F, Bidlingmaier C, Garagiola I. Management of pregnancy and delivery in women with inherited bleeding disorders. Semin Fetal Neonatal Med 2011; 16: 311-7.

20. Sainio S, Kekomäki R, Riikonen S, Teramo K. Maternal thrombocytopenia at term: a population-based study. Acta Obstet Gynecol Scand 2000; 79: 744-9.

21. Harrop-Griffiths W, Cook TM, Gill H, Hill D, Ingram M, Makris $\mathrm{M}$, et al. Regional anaesthesia and patients with abnormalities of coagulation: the Association of Anaesthetists of Great Britain \& Ireland The Obstetric Anaesthetists' Association Regional Anaesthesia UK. Anaesthesia 2013; 68: 966-72.

22. Davies JR, Fernando R, Hallworth SP. Hemostatic function in healthy pregnant and preeclamptic women: an assessment using the platelet function analyzer (PFA-100) and thromboelastograph. Anesth Analg 2007; 104: 416-20.

23. Lao TT, Halpern SH, MacDonald D, Huh C. Spinal subdural haematoma in a parturient after attempted epidural anaesthesia. Can J Anaesth 1993; 40: 340-5.

24. Rolbin SH, Abbott D, Musclow E, Papsin F, Lie LM, Freedman J. Epidural anesthesia in pregnant patients with low platelet counts. Obstet Gynecol 1988; 71: 918-20.

25. Sharma SK, Philip J, Whitten CW, Padakandla UB, Landers DF. Assessment of changes in coagulation in parturients with preeclampsia using thromboelastography. Anesthesiology 1999; 90: 385-90.

26. Kam PC, Thompson SA, Liew AC. Thrombocytopenia in the parturient. Anaesthesia 2004; 59: 255-64.

27. Maslow AD, Breen TW, Sarna MC, Soni AK, Watkins J, Oriol NE. Prevalence of coagulation abnormalities associated with intrauterine fetal death. Can J Anaesth 1996; 43: 1237-43.

28. Moen V, Dahlgren N, Irestedt L. Severe neurological complications after central neuraxial blockades in Sweden 1990-1999. Anesthesiology 2004; 101: 950-9.

29. Markley JC, Farber MK, Perlman NC, Carusi DA. Neuraxial anesthesia during cesarean delivery for placenta previa with suspected morbidly adherent placenta: a retrospective analysis. Anesth Analg 2018; 127: 930-8.

30. Mhyre JM, Shilkrut A, Kuklina EV, Callaghan WM, Creanga AA, Kaminsky S, et al. Massive blood transfusion during hospitalization for delivery in New York State, 1998-2007. Obstet Gynecol 2013; 122: 1288-94.

31. Holcomb JB, del Junco DJ, Fox EE, Wade CE, Cohen MJ, Schreiber MA, et al. The prospective, observational, multicenter, major trauma transfusion (PROMMTT) study: comparative effectiveness of a time-varying treatment with competing risks. JAMA Surg 2013; 148: 127-36.

32. Pasquier P, Gayat E, Rackelboom T, La Rosa J, Tashkandi A, Tes- 
niere A, et al. An observational study of the fresh frozen plasma: red blood cell ratio in postpartum hemorrhage. Anesth Analg 2013; 116: 155-61.

33. Holcomb JB, Tilley BC, Baraniuk S, Fox EE, Wade CE, Podbielski JM, et al. Transfusion of plasma, platelets, and red blood cells in a 1:1:1 vs a 1:1:2 ratio and mortality in patients with severe trauma: the PROPPR randomized clinical trial. JAMA 2015; 313: 471-82.

34. Collins P, Abdul-Kadir R, Thachil J. Management of coagulopathy associated with postpartum hemorrhage: guidance from the SSC of the ISTH. J Thromb Haemost 2016; 14: 205-10.

35. Johansson PI, Stensballe J, Rasmussen LS, Ostrowski SR. A high admission syndecan-1 level, a marker of endothelial glycocalyx degradation, is associated with inflammation, protein $\mathrm{C}$ depletion, fibrinolysis, and increased mortality in trauma patients. Ann Surg 2011; 254: 194-200.

36. Ostrowski SR, Johansson PI. Endothelial glycocalyx degradation induces endogenous heparinization in patients with severe injury and early traumatic coagulopathy. J Trauma Acute Care Surg 2012; 73: 60-6.

37. Hofmann-Kiefer KF, Knabl J, Martinoff N, Schiessl B, Conzen $\mathrm{P}, \mathrm{Rehm} \mathrm{M}$, et al. Increased serum concentrations of circulating glycocalyx components in HELLP syndrome compared to healthy pregnancy: an observational study. Reprod Sci 2013; 20:
$318-25$.

38. Henry DA, Carless PA, Moxey AJ, O'Connell D, Stokes BJ, Fergusson DA, et al. Anti-fibrinolytic use for minimising perioperative allogeneic blood transfusion. Cochrane Database Syst Rev 2011; (3): CD001886.

39. Ferrer P, Roberts I, Sydenham E, Blackhall K, Shakur H. Antifibrinolytic agents in post partum haemorrhage: a systematic review. BMC Pregnancy Childbirth 2009; 9: 29.

40. WOMAN Trial Collaborators. Effect of early tranexamic acid administration on mortality, hysterectomy, and other morbidities in women with post-partum haemorrhage (WOMAN): an international, randomised, double-blind, placebo-controlled trial. Lancet 2017; 389: 2105-16.

41. Levy JH, Welsby I, Goodnough LT. Fibrinogen as a therapeutic target for bleeding: a review of critical levels and replacement therapy. Transfusion 2014; 54: 1389-405.

42. Butwick AJ. Postpartum hemorrhage and low fibrinogen levels: the past, present and future. Int J Obstet Anesth 2013; 22: 87-91.

43. Park SW. Diagnosis and management of postpartum hemorrhage. Anesth Pain Med 2013; 8: 209-15.

44. Wikkelsø AJ, Edwards HM, Afshari A, Stensballe J, Langhoff-Roos J, Albrechtsen C, et al. Pre-emptive treatment with fibrinogen concentrate for postpartum haemorrhage: randomized controlled trial. Br J Anaesth 2015; 114: 623-33. 